\title{
Mercado Institucional e Políticas Territoriais: a experiência dos agricultores familiares da comunidade de Matinha na zona rural de São Luís/MA
}

\author{
Zulene Muniz Barbosa \\ Universidade Estadual do Maranhão - São Luís -MA- Brasil \\ ORCID: https://orcid.org/0000-0002-5464-6881 \\ Bianca Sampaio Corrêa \\ Instituto de Educação, Ciência e Tecnologia do Maranhão - Bacabeira - MA - \\ Brasil \\ ORCID: https://orcid.org/0000-0001-7677-4684
}

\begin{abstract}
Resumo
Este artigo analisa a experiência dos agricultores familiares de Matinha, na zona rural de São Luís (MA), a partir da implantação dos mercados institucionais, como se reconhecem no processo de produção, as transformações nas unidades produtivas à retomada e ampliação dos cultivos tradicionais e diversificação produtiva, a fim de verificar quais as implicações socioeconômicas do PAA nas relações de comercialização dos alimentos produzidos pelos agricultores, mediante a sua operacionalização gestada sob a articulação no âmbito da esfera federal, estadual e municipal. Para atingir este objetivo, nos anos de 2017 e 2018, foram realizadas entrevistas com 12 agricultores, com as coordenadoras do PAA a nível municipal e estadual e o coordenador de logística do programa. Os resultados e conclusão, revelam que a inserção dos agricultores de Matinha no mercado institucional, representou significativas mudanças, por um lado, nas suas diversas formas de organização da produção e, consequentemente, na escoação dos alimentos, e por outro, o acesso ao programa expressa ainda alguns entraves para estes agricultores, em virtude de exigências burocráticas e de contingenciamento de recursos financeiros, desde 2017, que se acentuou no atual contexto do governo Bolsonaro.
\end{abstract}

Palavras-chave: Agricultura familiar. Mercado institucional. Políticas territoriais. PAA.

Institutional Market and Territorial Policies: the experience of family farmers in the community of Matinha in the rural area of São Luís / MA

Abstract

This article analyzes the experience of family farmers in Matinha, in the rural area of São Luís (MA), from the establishment of institutional markets, as recognized in the production process, the transformations in the production units to the resumption and expansion of 
traditional crops and productive diversification, in order to verify what are the socioeconomic implications of the PAA in the relations of commercialization of the food produced by the farmers, through its operationalization managed under the articulation at the federal, state and municipal level. To achieve this goal, in the years 2017 and 2018, interviews were conducted with 12 farmers, with the coordinators of the PAA at the municipal and state level and the coordinator of the program's logistics. The results and conclusion show that the insertion of Matinha's farmers in the institutional market represented significant changes, on the one hand, in their various forms of organization of production and, consequently, in the disposal of food, and on the other hand, access to the program. it also expresses some obstacles for these farmers, due to bureaucratic requirements and contingency of financial resources, since 2017, which has been accentuated in the current context of the Bolsonaro government.

Keywords: Family farming. Institutional market. Territorial policies. PAA.

\section{Mercado institucional y políticas territoriales: la experiencia de los agricultores familiares en la comunidad de Matinha en la zona rural de São Luís / MA}

\section{Resumen}

Este artículo analiza la experiencia de los agricultores familiares en Matinha, en el área rural de São Luís (MA), desde el establecimiento de mercados institucionales, reconocidos en el proceso productivo, las transformaciones en las unidades de producción hasta la reanudación y expansión de cultivos tradicionales y diversificación productiva, con el fin de verificar cuáles son las implicaciones socioeconómicas del PAA en las relaciones de comercialización de los alimentos producidos por los agricultores, a través de su operacionalización gestionada bajo la articulación a nivel federal, estatal y municipal. Para lograr este objetivo, en los años 2017 y 2018 se realizaron entrevistas a 12 agricultores, con los coordinadores del PAA a nivel municipal y estatal y el coordinador de logística del programa. Los resultados y conclusión muestran que la inserción de los agricultores de Matinha en el mercado institucional representó cambios significativos, por un lado, en sus diversas formas de organización de la producción y, consecuentemente, en la disposición de los alimentos, y por otro, el acceso al programa. también expresa algunos obstáculos para estos agricultores, por exigencias burocráticas y contingencia de recursos financieros, desde 2017, lo que se ha acentuado en el contexto actual del gobierno de Bolsonaro.

Palabras clave: Agricultura Familiar. Mercado institucional. Políticas territoriais. PAA.

\section{Introdução}

No Brasil, a agricultura familiar como forma de produção foi historicamente marginalizada como consequência, tanto, da herança colonial como do processo de "Modernização conservadora" da agricultura brasileira. Este artigo analisa a experiência dos agricultores familiares de Matinha', na zona rural de São Luís (MA),

\footnotetext{
${ }^{1}$ A comunidade de Matinha resultou de um processo de ocupação, que ocorreu em 1978 e adquiriu este nome, devido existência na área ocupada de uma grande extensão de mata. Atualmente, vivem em Matinha 193 famílias que possuem na atividade agrícola o seu principal meio de reprodução econômica, através da produção de hortifrutigranjeira.
} 
em mercados institucionais e as implicações socioeconômicas das suas atividades produtivas por meio do Programa de aquisição de Alimentos ${ }^{22}$.

O artigo está organizado em cinco seções a contar da presente introdução. A segunda seção constitui o marco operacional e conceitual a partir do qual são apresentadas definições centrais que darão suporte à análise, onde discutimos a abordagem da construção das políticas públicas territoriais no âmbito do Programa Fome Zero- PFZ, desenvolvido nos governos Lula e Dilma. Na seção três apresentamos de um lado, a evolução do PAA, comparando os dados das modalidades de acesso ao programa, visando demonstrar aspectos dessa política que contribuíram para o fortalecimento da agricultura familiar e, do outro, os impactos da redução de recursos para a implementação do programa no âmbito do governo Bolsonaro. Na seção subsequente, fazemos uma breve caracterização da comunidade de Matinha, e a sua experiência de acesso ao PAA, quanto as suas atividades produtivas mediante o tipo de comercialização baseada, na modalidade compra e doação simultânea de alimentos. Na conclusão, retomamos o debate acerca das contribuições e entraves que os agricultores enfrentam na inserção no mercado institucional.

Nos anos 1990, como resultado da pressão dos movimentos sociais do campo aparece as primeiras iniciativas de políticas públicas voltadas para a agricultura familiar. A criação do Programa Nacional de Fortalecimento da Agricultura Familiar (PRONAF), em 1995, e sua institucionalização, em 1996, representou a primeira iniciativa realizada neste sentido, suscitando a emergência anos mais tarde de outras ações voltadas ao fortalecimento da agricultura familiar e a redução de sua vulnerabilidade social e econômica. Deve ser destacado nesse processo a criação do Ministério do Desenvolvimento Agrário (MDA), em 1999.

Concomitantemente a essas ações, foram elaboradas políticas públicas pautadas na criação de mercados institucionais para a agricultura familiar e voltadas para a segurança alimentar e nutricional de populações em situação de risco e vulnerabilidade social, como o Programa de Aquisição de Alimentos (PAA), criado em 2003, no início do governo Lula. Este programa surge no âmbito da política de segurança alimentar, Fome Zero, concebido como estratégia do governo federal referente ao mercado institucional de alimentos. A partir de 2012, os mercados para os produtos de alimentos da agricultura familiar foram novamente ampliados com a criação de mais uma modalidade do PAA, denominada Compra Institucional, a qual permite às instituições federais, estaduais e municipais adquirir alimentos de produtores familiares através de chamadas públicas, as quais têm um nível de exigência bem inferior do que os processos licitatórios previstos na Lei 8.666, instituída no ano de 1993.

De acordo com Grisa e Schneider (2015), programas como o PAA têm estimulado os governos estaduais e municipais a criarem seus próprios mecanismos de compras públicas, além de contribuir para a valorização da produção local/regional, ecológica/orgânica e promover ações de justiça social, equidade e qualificação dos produtos da agricultura familiar.

\footnotetext{
${ }^{2}$ Esta pesquisa foi realizada entre os meses de agosto de 2017 a fevereiro de 2018, no âmbito do Programa de Pós graduação em Desenvolvimento Socio espacial e regional da Universidade Estadual do Maranhão.
} 
Apesar dos avanços alcançados ao longo da última década, os agricultores familiares ainda têm encontrado dificuldades para se manterem ou mesmo se inserirem no programa, enfrentando restrições como a falta de conhecimento sobre os mesmos, a burocracia de acesso, o contingenciamento do orçamento financeiro, entre outros.

Diante desse contexto, procuramos verificar as estratégias de comercialização desenvolvidas pelos agricultores familiares de Matinha e as mudanças na sua organização produtiva, por meio da operacionalização do PAA, na modalidade "Compra e Doação Simultânea".

Para tanto, na apreensão da particularidade do objeto, a perspectiva consistiu em compreender a realidade a partir das suas contradições e dos modos de produção existente no Maranhão, muito embora as relações capitalistas, aqui, subordinem todas os outros modos de produzir. Assim, considerando a construção do conhecimento científico, as categorias analíticas totalidade, contradição e história se constituíram fundamentais na análise do objeto de estudo em questão. Como procedimentos metodológicos realizamos leituras, cujo arcabouço teóricoconceitual possibilitou analisar e refletir acerca da realidade empírica dos agricultores familiares por meio de entrevistas semi-estruturadas com 12 agricultores de Matinha, três coordenadores das respectivas secretarias municipal e estadual $^{33}$, que operacionalizam a política pública de comercialização do Programa de Aquisição de Alimentos (PAA).

As entrevistas, portanto, combinaram perguntas fechadas e abertas com roteiros pré-estabelecidos, o que possibilitou ao entrevistado relatar as suas experiências vivenciadas. Todas as informações obtidas, foram sistematizadas, organizadas e classificadas com o uso da categorização para ampliar a capacidade de análise dos dados qualitativos e quantitativos obtidos e apresentados em forma de gráficos e quadros.

\section{As políticas territoriais nos contextos dos governos Lula e Dilma}

A construção da trajetória das políticas de desenvolvimento territorial até a primeira metade da década 1980, se constituíam de forma mais centralizada. Na sua segunda metade, a questão da territorialização e da governança como espaço de relações econômicas e sociais e viabilidade dos processos de descentralização das políticas públicas, passam a ter um papel substantivo no processo de redemocratização. A perspectiva da descentralização e da ampliação do espaço público reivindicada pelos movimentos sociais, especificamente, as organizações sociais do campo contribuíram para ampliar o campo da política, redefinindo as relações entre governo e sociedade civil.

A criação do Pronaf, em 1995, representou o reconhecimento e a legitimação do Estado em relação às especificidades de uma nova categoria social, o agricultor familiar. A referida política pública mesmo sendo uma novidade histórica tem sido marcado por avanços e ambiguidades. O estudo pioneiro da FAO trouxe uma importante contribuição ao debate político ao definir com maior precisão conceitual

\footnotetext{
${ }^{3}$ Uma coordenadora da Secretaria de Agricultura Familiar (SAF), um coordenador logístico e uma coordenadora do PAA pertencentes à Secretaria Municipal de Segurança Alimentar (SEMSA).
} 
o termo agricultura familiar, mostrando sua importância socioeconômica. E, mais que isso, este estudo apresentou um conjunto de diretrizes que apontava a expansão e o fortalecimento deste segmento social específico como uma estratégia viável para construir um novo modelo de desenvolvimento rural no Brasil.

A conjugação dos acontecimentos mencionados, foram decisivos para iniciar uma mudança marcante do setor público brasileiro em relação ao campo. O Pronaf foi instituído oficialmente através do decreto presidencial $n^{\circ} 1.946$, de junho de 1996 - como segmento gerador de emprego e renda, de modo a estabelecer um novo padrão de desenvolvimento sustentável, o alcance de níveis de satisfação e o bem-estar de agricultores e consumidores, no que se refere às questões econômicas, sociais e ambientais. Foi, então, durante as gestões dos governos Lula e Dilma Rousseff (2003 a 2014), que os critérios de distribuição do crédito rural foram totalmente reformulados, visando, adequar a estrutura normativa do programa à diversidade da agricultura familiar e ampliar a sua capilaridade nacional (AQUINO; SCHNEIDER, 2015).

Com isso a categoria de agricultores familiares passou para o centro da cena e a discussão sobre políticas públicas para o campo, assumindo uma nova configuração política. Discussões relevantes a respeito da produção agrícola, técnicas, comercialização, agro industrialização, preços e crédito, associativismo, meio ambiente foram redimensionados, ganhando força especialmente no movimento sindical a ideia de um projeto alternativo de desenvolvimento rural com base na agricultura familiar.

Delgado (2010) chama atenção para o fato de que década de 1990, deixou um legado de disputa entre dois projetos políticos: o projeto neoliberal do agronegócio, pautado, fundamentalmente, pela expansão da agricultura de exportação estruturalmente complementar ao ajustamento constrangido à globalização e o projeto democrático representado, inicialmente, no meio rural pela proposta da reforma agrária e de desenvolvimento rural fundado na agricultura familiar. Nessa disputa, se afirmou de um lado, a expansão da agricultura do mercado interno, do reconhecimento dos direitos sociais das populações rurais, da democratização do acesso às políticas públicas de segurança alimentar e nutricional e, do outro, a cultura do agronegócio que, também, ganhou espaço substancial com suas entidades empresariais agro negocistas.

Cabe ressaltar que o processo de modernização conservadora no Maranhão a partir da política governamental adotada logo após o golpe militar de 1964, implementado pela a oligarquia Sarney se intensificou no período neoliberal, em relação a um conjunto de atividades econômicas, de modo particular, o setor agropecuário. Conforme analisa Barbosa (2003), na análise desse processo é importante compreender o Maranhão como parte constitutiva de uma totalidade: a sociedade brasileira com seus vínculos de dependência externa e de subordinação ao capitalismo internacional. O intuito de modernizar o setor agrícola foi sem dúvida a principal engrenagem no aumento da produção e produtividade para setores do capital. Na prática, os investimentos, no crédito rural e as políticas macroeconômicas beneficiaram muito mais a área mais dinâmica da economia (a indústria) e da região mais desenvolvida (Sul/Sudeste) do que as regiões periféricas como Norte e o Nordeste. 
No início dos anos 2000, por conseguinte, emergiram os diversos conselhos municipais e estaduais, tanto urbanos quanto rurais, como o Conselho Nacional de Segurança Alimentar e Nutricional (CONSEA), com o objetivo de subsidiar a formulação das políticas públicas sob responsabilidade do Ministério de Desenvolvimento Agrário. A elaboração de políticas públicas direcionadas ao meio rural passam a ter como exigência para a sua operacionalização, novos instrumentos de intervenção pública que articule a dinâmica institucional da agricultura familiar aos objetivos dos territórios rurais.

Efetivamente a partir do governo Lula, as políticas de desenvolvimento territoriais buscam o fortalecimento e valorização da agricultura familiar por meio das ações de reforma agrária, a exemplo, do crédito diferenciado ofertado a partir da criação do Programa Nacional de Fortalecimento da Agricultura Familiar PRONAF. O auge foi a criação do Ministério do Desenvolvimento Agrário - MDA que através do PRONAF e do Plano de Desenvolvimento Sustentável dos Territórios Rurais - PDSTR são responsáveis por grande parte das políticas de apoio à agricultura familiar e, do Ministério do Desenvolvimento Social e Combate a Fome MDS, que respondem pelo Programa Fome Zero - PFZ.

No documento Fome Zero, uma Proposta de Política de Segurança Alimentar para o Brasil, elaborado pelo Instituto Cidadania, em 2003, foram mapeadas as principais ações de intervenção do Estado para a promoção da agricultura familiar e da segurança alimentar e uma das primeiras medidas adotadas foi o PLANAF, instituído como uma modalidade de crédito rural pelo Banco Central em 1996, foi posteriormente intitulada de Programa Nacional de Fortalecimento da Agricultura Familiar - PRONAF.

Foi dentro desse contexto que surgem nos governos Lula e Dilma as chamadas políticas territoriais para o desenvolvimento rural: o PRONAT e o PTC. A elaboração da proposta da PDBR, coordenada pelo CONDRAF (Conselho Nacional de Desenvolvimento Rural Sustentável), com base nos princípios da soberania, sustentabilidade, inclusão, diversidade, igualdade, solidariedade e democracia; e quatro diretrizes estratégicas que se complementam e se integram, são elas: potencialização da diversidade e da multifuncionalidade dos espaços rurais; dinamização econômica, inovações tecnológicas e sustentabilidade; qualidade de vida com inclusão social igualdade de oportunidades; e fortalecimento do Estado, com o protagonismo dos atores locais e gestão social.

O recorte territorial e a articulação de políticas públicas destinadas ao meio rural, por meio de governança publica foi potencializada. Desenvolveu-se por meio Ministério do Desenvolvimento Agrário (MDA) um conjunto de ações estratégicas no âmbito da inclusão produtiva, com o objetivo primordial de pautar uma nova cultura política no meio rural centrada numa maior autonomia de agricultores familiares, assentados da reforma agrária e de povos e populações tradicionais. $O$ Programa Territórios da Cidadania (PTC) surgiu na perspectiva de reduzir pobreza no meio rural por meio de uma estratégia de desenvolvimento territorial sustentável.

Pode ser observado que a estratégia territorial se constitui numa das peças de enfrentamento da pobreza rural. O PRONAT (Programa de Desenvolvimento Sustentável dos Territórios Rurais) também conhecido como Territórios Rurais de Identidade passa a gerir um esquema de gestão, exclusivamente, centrado na 
SDT/MDA. Este programa passou a operar de forma regulamentada em julho de 2005, quando obteve sua chancela formal por intermédio da Portaria $n^{\circ} 5$, de 18/07/2005 vinculando os diferentes Colegiados Territoriais ao Ministério, o processo de gestão do programa Territórios da Cidadania estabeleceu um tripé: Comitê Gestor Nacional, Comitês de Articulação Estadual (CAE) e os Colegiados Estaduais (DELGADO; LEITE, 2015).

Convém salientar, que a política de desenvolvimento territorial no meio rural representou um avanço considerável, isto é, uma inovação institucional, ao implementar um formato mais adequado à ampliação da capacidade de participação social dos atores no processo de diálogo, negociação, desenho e planejamento de políticas públicas como um dos atributos da capacidade governativa e da gestão social dos processos de desenvolvimento.

Essa política, no entanto, apresentou-se de forma completamente desigual nas diversas experiências existentes, tanto no que tange ao seu grau de cobertura (a capacidade de inclusão dos mais diferentes atores locais) como no que se refere ao seu grau organizacional (a forma pela qual se deu a constituição efetiva dos espaços e procedimentos utilizados nas diferentes etapas do ciclo da gestão social) e também o seu grau de efetividade social (a representatividade e o alcance dos resultados alcançados, tanto em relação aos instrumentos adotados como em relação à forma como os mesmos foram empregados).

Em 2010, no início do governo Dilma foi lançado o Plano Brasil Sem Miséria (PBSM) o que colocou dúvidas quanto à continuidade do PTC e mesmo da adoção da abordagem territorial nas políticas públicas. Por outro lado, o MDA, não quis ou não teve condições de assumir uma postura mais firme na defesa da abordagem territorial e da inclusão dos territórios de cidadania na concepção estrutural do BSMR, de modo que aparentemente, a expectativa do MDA era maior do que o que acabou sendo incluído no Plano BSM (por razões orçamentárias e por divergências de concepção).

Delgado e Leite (2015) apontam que no PTC o foco de gestão centrou-se na articulação de políticas e de ações públicas, enquanto no BSM (e no BSMR), estes tiveram o seu foco de gestão centralizado no acompanhamento das famílias atendidas. Esta situação que pode ser observada, no início do governo Dilma, não significou que o rural tenha perdido relevância na agenda do governo. Tanto que o MDA passou a ser responsável pela implementação do PBSMR, incorporando, inclusive, à sua política territorial. Por outro lado, o PTC foi reativado através de medida editada pelo governo federal em novembro de 2011.

A partir de 2013, a política territorial recupera seu "próprio espaço" e busca reorientar-se de forma mais "autônoma" em relação às estratégias mais específicas das políticas sociais. No entanto, a continuidade dos programas territoriais continuaram assentados numa articulação institucional ainda frágil, sustentada por setores do governo federal que acreditam na capacidade de resposta diferenciada (por atuar via instâncias que contornam em parte os esquemas de poder local e por articular políticas de setores diversos) dessa política e por segmentos sociais na base dos territórios, oriundos de um acúmulo (ou de um capital social, terminologia muito usada na década de 1980) de experiências e aprendizados que se mobilizaram e se capitalizaram ao longo da construção dessas novas institucionalidades (DELGADO; LEITE, 2015). Estas entendidas, aqui, como o conjunto de regras de 
funcionamento, e de organizações colegiadas criadas para conduzir a gestão social e governança democrática a partir da escolha dos projetos estratégicos da política territorial, com a participação de representantes do Estado e da sociedade civil

Convém sublinhar, que a abordagem territorial para as políticas de desenvolvimento rural foi adotada pela SDT/MDA do primeiro governo Lula, em substituição à política dos governos anteriores que tinha o município como seu marco de referência principal. Esta mudança foi particularmente impactante pela extinção do Pronaf- Infraestrutura e Serviços, programa que canalizava recursos a fundo perdidos para municípios selecionados e que era implementado pelas prefeituras como supervisão e o controle feitos pelos Conselhos Municipais de Desenvolvimento Rural. A extinção do Pronaf Infraestrutura e Serviços e a canalização dos recursos para a política territorial reduziram o montante de financiamentos recebido pelos municípios anteriormente contemplados pelo programa. Isso fez com que as prefeituras e os Conselhos Municipais de Desenvolvimento Rural perdessem poder induzindo muitos prefeitos a se oporem à nova política territorial

No caso do Programa Territórios da Cidadania, oficializado em 2007, a institucionalidade territorial foi composta, por representantes do Estado e da sociedade civil. No âmbito desses territórios, a distribuição e o próprio princípio, paritária, exige uma composição ampliada em relação aos colegiados formados nos territórios rurais de identidade. Ou seja, os territórios da cidadania articulam uma participação mais ampliada de representantes das três esferas de governo (federal, estadual e municipal). Por outro lado, ainda que algumas experiências do Pronat tenham sido bem sucedidas e, outras, no que se refere ao Programa Territórios da Cidadania estejam em curso, são numerosos os casos em que os resultados têm sido modestos e reduzidos: em vários territórios os fóruns ou colegiados não se fazem representativos de todos os segmentos sociais da agricultura familiar local ou, ainda, os colegiados, em lugar de representarem espaços propícios à participação ampliada, figuram muito mais como estruturais impostas por determinadas políticas públicas para que os atores locais acessem recursos federais.

Esses espaços são conquistas importantes, entretanto, não raros acabam excluindo de sua dinâmica os segmentos menos articulados e mais carentes, reproduzindo a mesma estrutura preexistente de poder local e privilegiando alguns segmentos em detrimento de outros. Ainda são recorrentes os casos em que a abordagem de "desenvolvimento" sugerida limita-se, em sua maioria, a projetos setoriais e produtivos, excluindo de sua formulação a articulação da agricultura familiar com outros importantes segmentos sociais.

A partir do que foi exposto, considerando uma sociedade caracterizada pela concentração fundiária e de renda, em um contexto de descentralização políticoadministrativa e redemocratização do Estado, o que permite uma maior participação da sociedade civil, a experiência do PAA realizada na comunidade de Matinha apresenta características capazes de levar a um processo de desenvolvimento rural.

Nesse sentido, a descentralização política-administrava (pós-1988) contribuiu para a formação de diversas estruturas antes inexistentes, devido às atribuições dadas aos Estados e municípios. Nesse contexto, o papel dos conselhos municipais e das organizações da sociedade civil, ambas ligadas à agricultura familiar, tem sido 
substantivas nos processos de decisões, bem como no acesso às políticas públicas, neste caso, o PAA.

\section{O PAA como política pública de fortalecimento da agricultura familiar}

Como política pública, o Programa de Aquisição de Alimentos - PAA resultou de dois importantes debates concretizados na década de 1990: a segurança alimentar e nutricional e o reconhecimento por parte do governo federal da necessidade de fortalecer a agricultura familiar com base no Pronaf (Programa de Fortalecimento da Agricultura Familiar).

Esquecida na década neoliberal, esta proposta encontrou novos espaços durante o governo Lula, sendo uma das ações incluídas na estratégia de Segurança Alimentare Nutricional (SAN), articulada ao Programa Fome Zero. Este programa foi instituído pela Lei $\mathrm{N}^{\circ} 10.696$, de 2 de julho de 2003, regulamentada pelo Decreto $\mathrm{N}^{\circ} 4.772$ de 2 de julho de 2003, alterado pelo Decreto $\mathrm{N}^{\circ} 5.783$, de 15 de agosto de 2006. O PAA apresenta-se em cinco modalidades, destacamos aqui, a modalidade compra e doação simultânea, por meio da qual os agricultores de Matinha acessam oPAA.

A priori, cabe ressaltar a evolução do PAA no Brasil e no Maranhão. Dados recentes da CONAB (2017) apontam que o total de recursos provenientes do SEAD/MDS Secretaria Especial de Agricultura Familiar e do Desenvolvimento Agrário (SEAD) e do Ministério de Desenvolvimento Social, repassados em 2016, totalizou $\mathrm{R} \$$ 201.315.754,82. Esse recurso foi distribuído entre as modalidades Compra com Doação Simultânea - CDS (R\$ 183,9 milhões), Aquisição de Sementes (R\$ 4 milhões), Apoio à Formação de Estoques pela Agricultura Familiar - CPR Estoque ( $R \$ 9,5$ milhões) e recursos que envolvem a operacionalização do Programa ( $R \$ 2,7$ milhões), além das despesas com impostos. Os valores utilizados nas modalidades operacionalizadas pela CONAB possibilitaram a comercialização de 88.120 toneladas de alimentos produzidos por 29.318 agricultores familiares organizados em Cooperativas ou Associações que apresentaram 845 projetos.

O gráfico a seguir permite comparar a evolução dos investimentos feitos nas modalidades do PAA no período de 2009 a 2016.

Gráfico 1 - Evolução das modalidades do PAA de 2009 a 2016 (valor em mil reais)

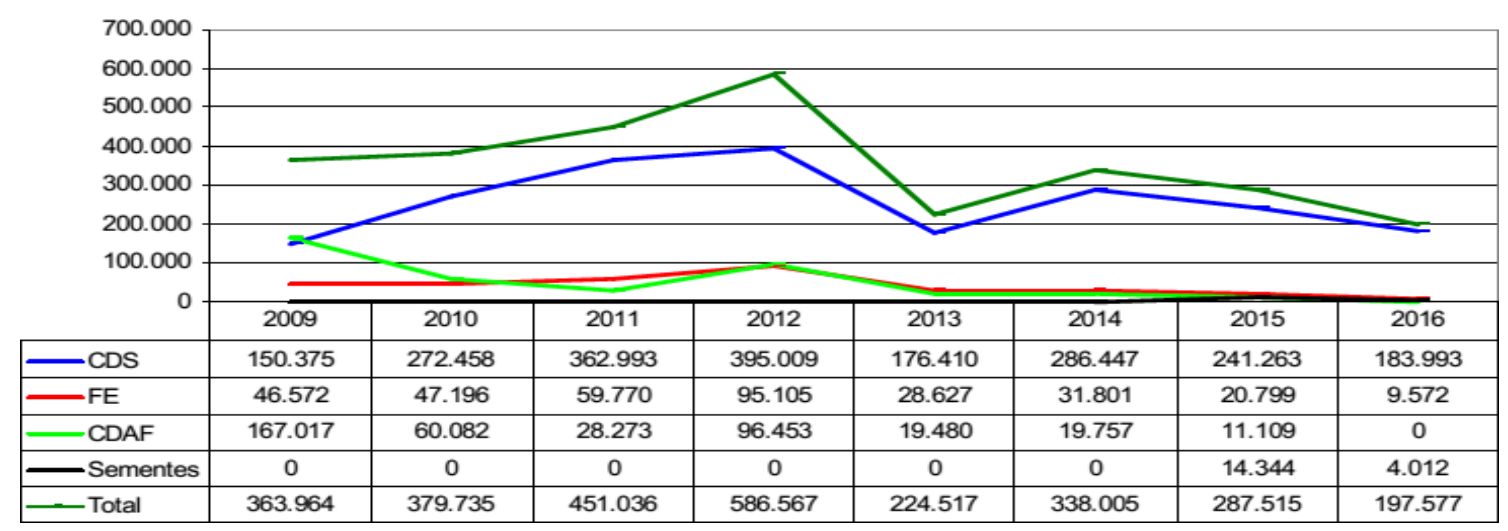

Fonte: CONAB, 2017. 
Os dados do gráfico 1 demonstram que o melhor desempenho do PAA em 2016 concentrou-se na modalidade Compra com Doação Simultânea, operacionalizado com recursos do MDS. Oêxito dessa modalidadeemrelaçãoàs demaisse deve ao seu desenho e às suas características, ao possibilitar a comercialização de produtos característicos da agricultura familiar, como hortaliças, frutas, doces, biscoitos caseiros, dentre outros, que são adquiridos por meio de Organizações Fornecedoras e entregues às Unidades Recebedoras (CONAB, 2017).

Segundo os dados do documento do estado pode-se verificar a evolução do PAA no período de 2012 a 2016, conforme demonstra o quadro 1:

Quadro1. Evolução do PAA no Maranhão, 2012 a 2016.

\begin{tabular}{|c|c|c|c|c|}
\hline \multicolumn{5}{|c|}{ Número de municípios adesos } \\
\hline 2012 & 2013 & 2014 & 2015 & 2016 \\
\hline 35 & 69 & 104 & & \\
\hline \multicolumn{5}{|c|}{ Número de municípios comercializando } \\
\hline 2012 & 2013 & 2014 & 2015 & 2016 \\
\hline 5 & 13 & 36 & & \\
\hline \multicolumn{5}{|c|}{ Número estimado de indivíduos vulneráveis atendidos } \\
\hline 2012 & 2013 & 2014 & 2015 & 2016 \\
\hline 6.031 & 31.884 & 45.000 & & \\
\hline \multicolumn{5}{|c|}{ Número de agricultores atendidos } \\
\hline 2012 & 2013 & 2014 & 2015 & 2016 \\
\hline 140 & 625 & 2.794 & 3.504 & \\
\hline \multicolumn{5}{|c|}{ Recurso aplicado (pago aos agricultores) - R\$ } \\
\hline 2012 & 2013 & 2014 & 2015 & 2016 \\
\hline $156.932,76$ & $1.679 .261,00$ & $6.055,021,15$ & $12.272 .900,02$ & \\
\hline
\end{tabular}

A partir desses dados verificou-se que houve um aumento do recurso aplicado no PAA e número de agricultores familiares atendidos. A coordenadora do PAA no Maranhão, afirmou que o Estado teve um investimento para a execução do programa no valor de 3 milhões de reais na etapa que se iniciou em 2017, prevista para se encerrar em maio de 2018. Afirmou, ainda, a coordenadora, que o estado recebeu mais 5 milhões em 2018, totalizando 12 milhões de reais para a implementação do programa junto aos municípios.

Quanto à execução do programa, a coordenadora do PAA, destacou que o município não consegue implantar o PAA sem a intermediação do estado (como ente federativo) porque existe normas quanto a execução do programa, no que tange à fiscalização e parâmetros de higienes dos produtos. Neste processo, o estado conta com o apoio da SUVISA (Superintendência de Vigilância Sanitária do Estado do Maranhão), que é a vigilância responsável em fazer com que o município possa emitir o alvará para o produtor poder acessar o programa.

A perspectiva aqui é localizar a ação do estado, pois no caso do PAA, os governos locais assumem um papel importante na implementação dessas políticas apesar destas serem formuladas no âmbito do governo federal. Não obstante, a atual conjuntura política do país desenhada desde 2017, com a extinção do Ministério do Desenvolvimento Agrário e a aplicação de uma política ultra neoliberal 
no setor, o cenário atual se mostra bastante desfavorável em função da redução de recursos para a ampliação do programa, como pode ser verificado em entrevista com a coordenadora do PAA, a qual relata que o governo federal afirmou que não havia muitas perspectivas positivas para o programa em 2018, diante da escassez de recurso.

Percebemos que de modo geral, o PAA, tem permitido a reorganização do trabalho familiar, a diversificação dos mecanismos de produção, comercialização e consumo, a partir da garantia de compras públicas. No entanto, desde 2017, o conjunto das mediações político-institucionais que garantiam a implementação desses mercados institucionais foram reestruturados. O aspecto crucial foi a extinção do Ministério do Desenvolvimento Agrário, (MDA) que foi incorporado, num primeiro momento, ao Ministério do Desenvolvimento Social (MDS), e depois foi reduzido a uma secretaria especial vinculada à Casa Civil.

Estas ações governamentais apontam para desestruturação da política de agricultura familiar que tiveram seu ponto máximo de investimentos no governo Lula. Observamos nesse sentido, sinais de retrocesso dessa política, de modo particular na comunidade rural de Matinha, pois o que antes possibilitava um planejamento produtivo e renda fixa, atualmente, devido à redução contínua de 300 agricultores para o número atual de 93 (entre 2014 - 2020) das adesões destes no PAA, tem gerado insegurança em relação ao quanto produzir comprometendo, assim, a reprodução social dos agricultores familiares.

\section{A experiência dos agricultores familiares de Matinha via mercado institucional}

A comunidade de Matinha está localizada no bairro Maracanã, próximo a BR135 na área peri-urbana a 18 km do centro de São Luís. Com aproximadamente 1.640 habitantes a sua principal atividade econômica é o cultivo de produtos hortifrutigranjeiros. O Maracanã tem características essencialmente rurais, localizado em uma Área de Proteção Ambiental (APA), criada pelo Decreto Estadual $\mathrm{n}^{\circ}$ 12.102/ 1991 e, uma área de 270 hectares, englobando os bairros: Maracanã, Vila Sarney, Vila Esperança e Rio Grande, e também o Parque da Juçara e o Viva Maracanã (Centro de eventos folclóricos).

Os moradores possuem um modo de vida próprio (cultura, sociabilidade, trabalho), em grande medida adaptado às condições ecológicas. Predomina em Matinha uma economia familiar e diversificada (agricultura, pesca, extrativismo, artesanato, comum calendário sazonal anual, conforme os recursos naturais explorados, normalmente, sob o regime familiar de organização do trabalho). Desde 2013, os moradores se organizaram para acessar os benefícios do PAA. Para tanto tiveram que cumprir com as exigências formais burocráticas do programa para a obtenção da DAP (Declaração de Aptidão ao Pronaf), documento que os identifica como agricultores familiares

No processo de organização exigido, consta que uma vez cadastrados, os beneficiários deverão se reunir uma vez por semana para discutir quais os produtos que deverão ser comercializados. Essa definição obedece a uma demanda estipulada pela Secretaria Municipal de Segurança Alimentar e Nutricional- SEMSA. 
As exigências burocráticas são apontadas pelos agricultores beneficiários de Matinha como algo que representa alguns dos entraves para o acesso ao programa, como pode ser evidenciado na seguinte fala:

Tem a questão financeira, de banco aí a gente percebe que tem muito agricultor que tem certa dificuldade de lidar com essas questões financeiras, bancárias, tem muitos agricultores que ainda não são letrados, então isso é um fator que pesa muito. Às vezes também o cartão que nunca veio, tem muitos agricultores que ainda não receberam seus cartões, sendo que pra essa etapa tem um prazo. E quando começar tem uma outra remessa com outros agricultores (ENTREVISTA, AB1, 2017).

Os relatos evidenciaram, também, os principais ganhos obtidos com a inserção dos agricultores ao programa. Foi relatado que um dos benefícios, foi a melhoria nas condições materiais das famílias. "Na questão da renda melhorou, e é mais valorizado os nossos produtos" (ENTREVISTA, AB2, 2017).

Outro aspecto destacado por um outro agricultor foi que o PAA, contribuiu para a permanência dos filhos no meio rural, sem a necessidade de buscar outras fontes de renda fora da comunidade.

Só o fato de dar uma melhorada na produção dos pais, os filhos podem começar tendo outra concepção, mas essa questão é muito milindrosa ainda, porque o êxodo rural do maranhão ele passa por um contexto educacional. Aqui no Maranhão a agricultura é 'chacota' é Bulling. Aliado a isso vem a falta de incentivo as políticas públicas no maranhão são muito tímidas. Primeiro a agricultura não dá voto né. Você pega um investimento público põe na agricultura é uma coisa que como a agricultura é uma coisa de alto risco, você investiu $R \$ 1.000 .000,00$ faz de conta que você não investiu quase nada (ENTREVISTA, AB3, 2017).

Percebemos pelos relatos dos beneficiários que o PAA consegue contribuir para que o tecido social seja mantido, inclusive, através da venda da produção, o que corrobora com Carneiro e Maluf (2003), quando enfatizam a identidade social como traço forte dos agricultores. Programa desse tipo, observa os autores, pode contribuir para que muitos jovens permaneçam no campo.

Algumas críticas foram ressaltadas em relação ao volume da produção a ser comercializada no âmbito do programa. Para os agricultores e agricultoras, deveria

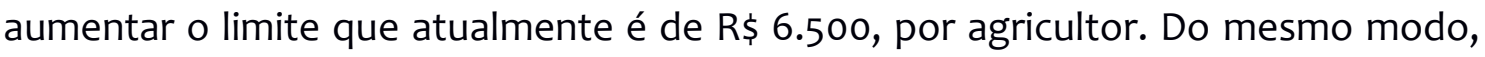
apontaram o fato do PAA ser apenas um programa e não uma política agrícola. "A gente corre o risco de o programa deixar de existir...Ele traz ânimo e incentivo, precisa ser mais ampliado" (ENTREVISTA, AB4, 2017).

A preocupação dos agricultores está ancorada no fato do PAA, não ser uma política de estado, logo não possui a estabilidade necessária para que o agricultor possa investir na produção de alimentos. E os mesmos demonstram receio quanto a possibilidade de extinção do programa:

[...] É uma renda a menos que a gente vai ter, a gente volta como vivia antes buscando mercado sozinho, embora sendo um ganho pouco, mas é um ganho que ajuda afinal você não consegue 6.mil reais assim fácil, mas às vezes aqui tá perto então pra você tirar da sua horta e trazer pra cá é mais fácil, que você ter que fretar um carro pra vender lá fora então tem essa dificuldade que com certeza vai afetar bastante (ENTREVISTA, AB5, 2018).

Pudemos observar que o PAA se mostra para os agricultores familiares de Matinha como um meio de acessar o mercado e escoar sua produção sem a necessidade de vendê-las para os atravessadores. 
Segundo relato dos agricultores e agricultoras o programa criou possibilidade de ampliar as relações para fora da comunidade, tais como feiras livres locais onde também os agricultores comercializam seus produtos. Estas, antes identificadas a um modelo arcaico de relações mercantis cuja extinção inevitável dependeria do ritmo de expansão das grandes redes varejistas, atualmente voltam a ocupar os espaços públicos de inúmeras cidades.

A partir do referencial analítico da teoria do desenvolvimento local e dos relatos de campo a implementação da política significou para os agricultores o alcance de uma situação (provisória) com um certo "empoderamento", visto que, em função de estarem organizados, puderam ter acesso aos recursos dos programas e passaram a vender a sua produção por um preço justo. Com isso, podese afirmar que eles passaram a deter um certo "poder" no tocante à superação das relações sociais de exploração a que estavam submetidos no processo de comercialização com os atravessadores.

Assim, considerando o PAA como uma política de desenvolvimento local, Grisa (2009) argumenta que o programa contribui para o fortalecimento dos capitais natural, cultural e social da agricultura familiar ao estimular a diversificação produtiva nos estabelecimentos rurais, a autonomia dos agricultores, e ainda uma ampla rede de atores da sociedade civil e de entidades públicas, visando incentivar o resgate e a preservação de costumes, hábitos e do saber-fazer das populações regionais, o que contribui para gerar um efeito catalisador do processo de empoderamento dos atores locais.

Em virtude dos alimentos serem produzidos e consumidos em localidades relativamente próximas, o PAA propicia a criação de circuitos curtos de comercialização, em contraponto aos circuitos longos e à desconexão entre produção e consumo, o que favorece a aproximação entre produtores e consumidores, a construção e o resgate de identidades, a valorização da cultura alimentar local/regional e do trabalho dos agricultores familiares, promovendo uma relação virtuosa de empoderamento deste grupo social e fortalecimento da segurança alimentar e nutricional de populações em situação de risco/vulnerabilidade social (GRISA; PORTO, 2015).

É importante sublinhar que na comunidade de Matinha, o PAA é operacionalizado através da modalidade compra e doação simultânea, estabelecendo-se via programa uma intrínseca relação entre produção, compra e consumo efetivada por meio da SEMSA (Secretaria de Segurança Alimentar), que compra os alimentos dos agricultores e os doa para as famílias de baixa renda atendida nos CRAS de vários bairros de São Luís. Sob a perspectiva da produção de alimentos, algumas estratégias como os circuitos locais de produção de alimentos viabilizaram a reconexão (produção-consumo. Desse modo, a circulação, seja na produção, seja no consumo de alimentos no âmbito local, potencializa ou oportuniza, também, outras relações sociais, econômicas e alimentares que vão além da simples resistência ao processo de desconexão do sistema agroalimentar.

O PAA dentro desse mercado institucional articula a produção de alimentos ao consumo local, respeitando a sazonalidade, a proximidade, os atributos de qualidade, o saber-fazer local contrapondo-se ao modelo de produção assentado em grandes corporações, que valoriza a distância, a padronização, a durabilidade dos produtos, a impessoalidade e subordina o tempo e o lugar à acumulação de 
capital. Na modalidade de "Compra e Doação Simultânea", produtores e consumidores encontram-se articulados e compreendem a importância que um tem para o outro, além da garantia de mercado.

Como sustentam Delgado et al. (2005), estes mercados institucionais têm colaborado para a recuperação dos preços regionais, havendo casos em que o simples anúncio da compra pública de um determinado produto é suficiente para elevar a sua cotação. Em algumas situações, o mercado local absorve a produção antes mesmo das compras públicas serem efetuadas, dispensando a efetivação das mesmas (é o caso das compras para a formação de estoques). Isso contribui para a autonomia dos agricultores em relação aos "atravessadores intermediários" ao assegurar a mediação entre consumo e produção.

$\mathrm{Na}$ comunidade de Matinha os agricultores estabelecem relações institucionais com a Secretaria Municipal de Segurança Alimentar (SEMSA) e isso tem contribuído com famílias, principalmente, na questão da logística de entrega de alimentos, pois não precisam fazer a entrega dos produtos ponto a ponto, conforme pode ser observado em entrevista realizada com umas das agricultoras cadastradas no PAA: "Agente não precisa de atravessador, a gente passa os produtos por um preço justo e sem contar que incentiva também a produção coisa que ficou extinta durante muitos anos aqui no Brasil, a questão da produção". (Entrevista, a1, 2017).

De acordo com a própria lógica do programa, outra questão que facilita a comercialização da produção na comunidade é a adequação dos produtos para a entrega, quanto à embalagem, rotulagem e adequação dos alimentos conforme a demanda. Na comunidade de Matinha os agricultores entregam os seus produtos na Associação de Moradores e Produtores Rurais (central de recebimento dos alimentos não só dos agricultores desta comunidade, mas de outras como Laranjeiras) e a SEMSA faz o processo de embalagem das cestas de alimentos para a entrega aos beneficiados consumidores - as famílias de baixa renda.

A Associação de Moradores é o local da organização coletiva dos agricultores - onde ocorre a entrega dos alimentos que serão destinados ao PAA nas seguintes etapas: primeiro faz-se a embalagem dos alimentos, depois os alimentos são pesados para então serem distribuídos. Existe uma relação institucional com referência à parte fiscal e a outras atividades burocráticas que envolvem a comercialização desses alimentos. A associação de moradores da comunidade de Matinha se torna, assim, um instrumento de diálogo entre os agricultores familiares e os órgãos públicos, facilitando a dinâmica da comercialização. Nesse processo alguns profissionais atuam diretamente no contato com as prefeituras e o órgão do estado, elaborando os projetos e adequando a comercialização à demanda apresentada.

No caso do processo de comercialização dos alimentos com a prefeitura existe um Termo de Recebimento e conforme afirma o coordenador logístico do PAA, este termo funciona como nota fiscal. Na SEMSA as informações referentes aos agricultores e alimentos são lançadas no sistema do governo federal e depois é emitida uma nota fiscal da Secretaria da Fazenda para então liberar o pagamento aos agricultores. Este termo é necessário para que o agricultor, não apenas entregue seus alimentos, mas também possa receber o pagamento. 
Quanto a este tipo de organização para a entrega dos alimentos alguns agricultores beneficiários relataram que antes do programa, existia a associação, porém não havia uma organização para a comercialização de alimentos. A SEMSA ao estipular um limite de produtos a ser entregue, uma vez por semana, estimulou uma maior organização desses agricultores no processo de comercialização dos seus produtos.

O Programa de Aquisição de Alimentos, cabe ressaltar, foi criado no município de São Luís em 2013, por meio do termo de adesão № 0526/2013 com a participação de representantes do governo do estado e do governo federal, entretanto é a instância municipal que executa o programa de acordo com as modalidades e metas pactuadas por meio de Planos Operacionais. O Programa conta ainda com a SEMAPA (Secretaria Municipal de Agricultura, Pesca e Abastecimento) para a sua execução. De acordo com informações disponibilizadas pela SEMSA, o PAA em São Luís é implementado na Modalidade Doação Simultânea, sendo responsabilidade da SEMAPA o cadastramento dos produtores, a garantia da assistência técnica e a realização do monitoramento das etapas de produção e certificação de atestado de qualidade dos produtos.

À SEMSA cabe a gestão, o recebimento e distribuição dos alimentos, além da prestação de contas dos produtos junto ao Ministério de Desenvolvimento Social e Combate à Fome- MDS. Nesta modalidade Doação Simultânea, a SEMSA recebe do próprio produtor os alimentos e entrega ao beneficiário, sem necessidade de armazenamento. Trata-se de um processo em que os agricultores podem vender, individualmente, até $\mathrm{R} \$ 6.500$, oo (seis mil e quinhentos reais) por unidade familiar/ano. O total dos recursos para a primeira etapa foi de $\mathrm{R} \$ 1.650 .000,00$.

De acordo com as informações junto a coordenadora do PAA-São Luís, na primeira etapa do programa, 300 agricultores foram cadastrados e distribuídos $377.412 \mathrm{~kg}$ de alimentos entre hospitais e associações inscritas nos CRAS, público beneficiado. Na segunda etapa iniciada em 2017, o valor investido no PAA pelo MDS diminuiu totalizando um valor de $\mathbf{1 . 1 5 5 . 0 0 0 , 0 0}$ reais e 178 agricultores cadastrados, havendo, pois, uma diminuição do número de agricultores atendidos. Foi distribuído até o mês de maio de 2017, o total de 47 toneladas de alimentos, considerando que nesta segunda etapa o público beneficiado foram apenas os CRAS, totalizando 2.160 famílias, isto é, 8.640 pessoas aproximadamente.

A coordenadora do PAA nos relatou que, no município de São Luís, o PAA está vinculado a 20 CRAS nos bairros: Anjo da Guarda, Sol e Mar, Cidade Operária, Vila Bacanga, Forquilha/Cohab, Anil, Bairro de Fátima, Centro, Cidade Olímpica, Coroadinho, Estiva, Janaína, João de Deus, Vila Nova, Vicente Fialho/Vinhais, São Raimundo, São Francisco, Maracanã, Liberdade, Vila Palmeira/Bequimão/Rio Anil. Acrescentou que os agricultores fornecedores dos alimentos a estes CRAS pertencem às seguintes comunidades: Matinha, Cassaco, Cajupary, Itapera, QuebraPote, Vila Nova República, Laranjeiras, Igaraú, Arraial, Terra do Rumo, Calembe, Coquilho I e II, Tajipuru, São Raimundo do Motor e Mato Grosso.

Observou-se a partir das entrevistas realizadas com os beneficiados do CRAS em diversos bairros da capital que o PAA, trouxe mais qualidade de vida no sentido de ajuda-los a consumir alimentos saudáveis. Quanto à entrega dos alimentos uma beneficiária consumidora $\mathrm{BC} 1$ entrevistada salientou que "o Programa é ótimo. 
Assim, tá fazendo um ano que a gente recebeu se fosse uma vez por mês seria melhor né”. (Entrevista, BC1, 2017).

\section{Conclusão}

A pesquisa de campo mostrou que o PAA traz elementos em sua concepção que apontam para um redirecionamento do entendimento sobre o papel que a agricultura familiar exerce no desenvolvimento da sociedade brasileira, principalmente nas perspectivas de desenvolvimento mais equitativo e que visa a incorporação de setores excluídos e sujeitos a situação de vulnerabilidades. Nesse sentido tem um forte impacto no modo de vida dos agricultores, particularmente frente às transformações socioculturais e institucionais sobre a terra, o trabalho e o mercado. São impactos positivos decorrentes do contexto recente desta estratégia de comercialização para a agricultura familiar nesta localidade.

Por conseguinte, conclui-se que o PAA contribui para o fortalecimento da agricultura familiar, a partir do foco no processo de comercialização, em que o agricultor tem para além do mercado livre, como as feiras, por exemplo, a oportunidade de ampliar a sua diversidade e quantitativo de produção, no caso para o programa via mercado institucional. Constatou-se que com a venda dos produtos no mercado institucional os produtos começaram a ser mais valorizado, de uma maneira geral, o que fez com que novas portas se abrissem para os agricultores familiares, ampliando, desta forma, os níveis de comercialização da agricultura familiar na comunidade. Porém, os limites de valor impostos para a compra dos produtos, as exigências burocráticas e a diminuição dos recursos financeiros para a execução sistemática do PAA, foram identificados como os principais gargalos do programa. Apesar dessas limitações, verificou-se o grande interesse demonstrado pelos agricultores familiares de Matinha em continuar participando do programa, pois, percebem a melhoria da receita familiar desta participação.

Com base neste arcabouço de elementos que subsidiam a análise dos dados, se pode concluir que o PAA, apesar de não ser uma política de Estado, mas, apenas uma política de governo, cumpre os objetivos que foi proposto e tem um peso significativo no fortalecimento da agricultura familiar e no seu desenvolvimento sustentável, porém, necessita de avanços no tocante ao reconhecimento da sua importância e na fundamentação e criação de uma política pública mais institucionalizada.

\section{REFERÊNCIAS}

AQUINO, J; SCHNEIDER, S. O Pronaf e o desenvolvimento rural brasileiro: avanços, contradições e desafios para o futuro. In: GRISA, C; SCHNEIDER, S. (Org.). Políticas públicas de desenvolvimento rural no Brasil. - Porto Alegre: Editora da UFRGS, 2015, p.53-76.

CARNEIRO, M. J.; MALUF, R.S (Org.). Para além da produção. Rio de Janeiro: MAUAD, 2003. 
CONAB - Companhia Nacional de Abastecimento. Programa de Aquisição de Alimentos - PAA: resultado das ações da CONAB em 2016. Brasília, 2017. Disponível em: https://www.conab.gov.br. Acesso em: 16 abr. 2018.

DELGADO, G; CONCEIÇÃO, J. C; OLIVEIRA, J. J. Avaliação do Programa de Aquisição de Alimentos da Agricultura Familiar. Brasília: IPEA, 2005. (Texto para discussão n. 1145). Disponível em: https://www.ipea.gov.br/. Acesso: 31 mai de 2020.

DELGADO, N. G.; LEITE, S. P. Políticas de Desenvolvimento Territorial: O Pronat e o PTC: possibilidades, limites e desafios das políticas territoriais para o desenvolvimento rural. In: GRISA, Catia e SCHNEIDER, Sergio (Org.) Políticas públicas de desenvolvimento rural no Brasil. Porto Alegre: Editora da UFRGS, 2015.p. 239- 260.

DELGADO, N. G. A “confluência perversa” de dois projetos contraditórios: projeto neoliberal e agronegócio e projeto democratizante, reforma agrária e novo modelo de desenvolvimento rural baseado na agricultura familiar. In: Brasil rural em debate: Brasília: CONDRAF/MDA, 2010.

GRISA, C.; SCHNEIDER, S. Três gerações de políticas públicas para a agricultura familiar e formas de interação entre sociedade e Estado no Brasil. In: GRISA, C.; SCHNEIDER, S. (Org.). Políticas públicas de desenvolvimento rural no Brasil. Porto Alegre: Editora da UFRGS, 2015. p. 19-50.

GRISA, C.; PORTO, S. I. As contribuições e os desafios para o desenvolvimento rural. In: GRISA, C.; SCHNEIDER, S. (Org.). Políticas públicas de desenvolvimento rural no Brasil. Porto Alegre: Editora da UFRGS, 2015. p. 155-180.

Zulene Muniz Barbosa. Doutora em Ciências Sociais pela Pontifícia Universidade Católica de São Paulo (PUC/SP). Professora da Universidade Estadual do Maranhão (CCSA) e coordenadora do Programa de Pós-Graduação em Desenvolvimento Socioespacial e Regional (PPDSR/UEMA), campus de São Luís-MA. Universidade Estadual do Maranhão, Centro de Educação e Ciências Naturais, Departamento de Ciências Sociais/Campus Universitário da UEMA: São Cristóvão, cep:65000-000, São Luís-MA.zulene.mb@uol.com.br

Bianca Sampaio Corrêa. Graduada em Ciências Sociais (CCSA/UEMA) e Mestre em desenvolvimento Socioespacial e Regional (PPDSR/UEMA). Professora do Instituto de Educação, Ciência e Tecnologia do Maranhão (IEMA), Campus Bacabeira-MA. Rua Eurípedes Bezerra, bairro Vicente Fialho, condomínio pacífico 3,bloco2,apartamento2,cep:65066260-SãoLuís-MA. biancasampaioc@hotmail.com 
Como citar: MUNIZ BARBOSA, Zulene; SAMPAIO CORREA, Bianca. Mercado Institucional e Políticas Territoriais: a experiência dos agricultores familiares da comunidade de Matinha na zona rural de São Luís/MA. Redes (St. Cruz Sul, Online), Santa Cruz do Sul, v. 25, p. 21852202, 2020. ISSN 1982-6745. doi:https://doi.org/10.17058/redes.v25io.15261.

\section{CONTRIBUIÇÃO DE CADA AUTOR}

Conceituação: Bianca Sampaio Corrêa e Zulene Muniz Barbosa.

Curadoria de Dados: Bianca Sampaio Corrêa.

Análise Formal: Bianca Sampaio Corrêa e Zulene Muniz Barbosa.

Obtenção de Financiamento: Não se aplica.

Investigação/Pesquisa: Bianca Sampaio Corrêa.

Metodologia: Bianca Sampaio Corrêa e Zulene Muniz Barbosa.

Administração do Projeto: Bianca Sampaio Corrêa e Zulene Muniz Barbosa.

Recursos: Não se aplica.

Software: Bianca Sampaio Corrêa e Zulene Muniz Barbosa.

Supervisão/orientação: Zulene Muniz Barbosa.

Validação: Zulene Muniz Barbosa.

Visualização: Bianca Sampaio Corrêa e Zulene Muniz Barbosa.

Escrita - Bianca Sampaio Corrêa.

Escrita - Zulene Muniz Barbosa.

Fontes de financiamento:

FAPEMA (Fundação de Amparo à Pesquisa e ao Desenvolvimento Científico e Tecnológico do Maranhão). 